\title{
Respon Masyarakat Desa Batu Cermin Dalam Pengembangan Daya Tarik Wisata Gua Batu Cermin, Labuan Bajo
}

Andriano Calrinto Mamia, 1, I Gusti Agung Oka Mahaganggaa, 2

1 andremami02@gmail.com, ${ }^{2}$ okamahagangga@unud.ac.id

a Program Studi S1 Destinasi Pariwisata, Fakultas Pariwisata,Universitas Udayana, Jl. Dr. R. Goris, Denpasar, Bali 80232 Indonesia

\begin{abstract}
The tourist attraction of Batu Cermin Cave is a tourist attraction located in the city center of Labuan Bajo. Attractions offered to tourists who end up in Batu Cermin Cave in the form of natural attractions along the Cave where there are Wisatawaan Stalagtics and Stalagmites who visit Batu Cermin Cave are dominated by tourists from the archipelago. For now the management of Batu Cermin Cave tourist attraction is still managed by the local government in this case is the West Manggarai District Tourism and Culture Service. Later the management of Batu Cermin Cave will involve the Batu Cermin village so that in this study we will discuss "The Response of Batu Cermin Village Community in the Development of Tourism Attractions in Batu Cermin Cave, Labuan Bajo".

The research method used in this study is a qualitative research method with qualitative descriptive data analysis techniques to explain the public response in the development of tourism in the tourist attraction of Batu Cermin Cave. The data source consists of primary data and secondary data. Data collection techniques using the method of observation, interviews and literature study. The determination of informants in this study used the Snowball technique.

The results obtained are the existing conditions of Batu Cermin Cave tourist attraction in the stages of involvement in Butler's theory and the response of the community of Batu Cermin village is still in the Aphaty phase in the Irridex theory
\end{abstract}

Keyword: Tourist Attraction, Batu Cermin Cave, Development of Tourism, Community Response, Travelers.

\section{PENDAHULUAN}

Dalam Rencana Kerja Pemertintahan (RKP) 2018 Presiden RI Joko Widodo telah menetapkan pariwisata sebagai sektor unggulan. Pada masa pemerintahan Presiden Jokowi juga telah ditetapkan 10 destinasi Bali baru untuk mendukung sektor pariwisata. Menteri Pariwisata RI Arief Yahya menyatakan telah melaksanakan pengembangan 10 destinasi pariwisata prioritas atau 10 Bali Baru. Program ini menjadi ujung tombak pemerintah RI dalam menetapkan target 20 Juta wisatawan di tahun 2019 (Mahagangga, dkk. 2019).

Labuan Bajo merupakan salah satu dari 10 Bali baru. Terdapat banyak daya tarik wisata yang menarik minat wisatawan untuk berkunjung. Salah satu daya tarik wisata yang menarik untuk dikunjungi adalah Gua Batu Cermin (Mirror cave). Gua Batu Cermin ditemukan pada tahun 1951 oleh Theodore Verhoven seorang arkeolog dari Belanda dimana Verhoven berasumsi bahwa dahulu kala Labuan Bajo berada dibawah laut karena temuan fosil satwa di dinding gua.

Berdasarkan Data Kunjungan Wisatawan Ke Objek Daya Tarik Wisata Manggarai Barat (Gua Batu Cermin) bulan Januari - Juni tahun 2017 dan 2018 yang dibagi menjadi wisatawan manca Negara, wisatawan nusantara dan wisatawan lokal disebutkan bahwa jumlah kunjungan pada Tahun 2017, wisatawan manca Negara berjumlah 1.295 orang, wisatawan nusantara berjumlah 3.731 orang dan wisatawan lokal berjumlah 107 orang. Jumlah kunjungan pada Tahun 2018, wisatawan manca Negara berjumlah 1.770, wisatawan nusantara berjumlah 4.841 orang, wisatawan lokal berjumlah 1.745. Jumlah total Kunjungan Wisatawan Ke Objek Daya Tarik Wisata Manggarai Barat (Gua Batu Cermin) pada dua tahun terakhir yaitu Wisatawan Mancanegara dengan total 3.065 orang, wisatawan nusantara berjumlah 8.572 orang dan wisatawan lokal berjumlah 1.852 orang. Jika dilihat dari data kunjungan terakhir dapat disimpulkan bahwa yang mendominasi kunjungan ke Gua Batu cermin adalah wisatawan Nusantara. Kunjungan wisatawan ke Gua Batu Cermin yang semakin meningkat setiap tahun, oleh karena itu pemerintah Kabupaten Manggarai Barat menetapkan Gua Batu Cermin sebagai daya tarik wisata, namun dalam pengembangannya baik dari perencanaan, fasilitas dan produk pariwisata bisa dibilang cukup memadai.

Dalam upaya mengembangkan suatu Destinasi dibutuhkan kerjasama antara beberapa pihak sehingga pengembangan suatu Destinasi bisa optimal. Pengembangan daya tarik wisata Gua batu Cermin dilakukan oleh Dinas Kebudayaan dan Pariwisata dalam hal ini adalah Pemerintah Daerah Kabupaten Manggarai Barat. Pada Tahun 2019 ini Dinas Kebudayaan dan Pariwisata akan bekerja sama dengan Desa Batu Cermin dalam pengelolaan daya tarik wisata Gua Batu Cermin. Akan tetapi minimnya keikutsertaan masyarakat lokal dalam pengembangan daya tarik wisata Gua Batu Cermin berakibat pada pengembangan yang tidak optimal. 
Vol. 8 No 1, 2019

Peran dari masyarakat lokal tidak kalah pentingnya dalam pengembangan daya tarik wisata Gua Batu Cermin. Respon dari masyarakat Desa Batu Cermin merupakan pencerminan sikap masyarakat terhadap perkembangan daya tarik wisata ini. Respon yang baik dari masyarakat akan memberikan dampak positif dalam pengembangan destinasi wisata, begitupun sebaliknya, oleh karena itu peneliti mengambil topik penelitian tentang Respon masyarakat untuk mengidentifikasi seperti apa Respon Masyarakat Desa Batu Cermin dalam pengembangan daya tarik wisata Gua Batu Cermin, Labuan Bajo.

\section{TINJAUAN PUSTAKA}

Telaah penelitian yang dilakukan sebelumnya sangat penting guna mengetahui posisi penelitian yang dilakukan pada penelitian ini dengan penelitian sebelumnya. penelitian pertama yang diteliti oleh Karnayanti dan Mahagangga (2019), penelitian kedua yang dijadikan acuan adalah penelitian yang dilakukan oleh Budiningtyas(2013).

Berdasarkan kajian dari kedua telaah penelitian sebelumnya dapat disimpulkan, bahwa penelitian terkait Respon Masyarakat Desa Batu Cermin dalam Pengembangan Daya Tarik Wisata Gua Batu Cermin, Labuan Bajo sangat penting untuk dilakukan.

Penelitian ini menggunakan konsep Pengembangan merujuk pada Yoeti (Yoeti, 1996) dan konsep Respon Masyarakat (Susanto, 1998).

\section{METODE PENELITIAN}

Penelitian ini dilakukan di Daya Tarik Wisata Gua Batu Cermin, Kecamatan Komodo, Kabupaten Manggarai Barat. Daya tarik wisata ini memiliki keunggulan jika dilihat dari lokasinya dibandingkan dengan daya tarik wisata yang lainnya di Labuan Bajo karena berada dipusat kota. Adapun ruang lingkup penelitian yang digunakan untuk mempertegas batas lingkup permasalahan yaitu, Respon masyarakat lokal dalam pengembangan daya tarik wisata Gua Batu Cermin yang dapat dilihat dari beberapa aspek meliputi respon masyarakat lokal terhadap pemerintah, respon masyarakat lokal terhadap pihak swasta, respon masyarakat lokal terhadap wisatawan

Jenis dan sumber data dalam penelitian ini menggunakan jenis data kualitatif (Moleong, 2012) yang meliputi : gambaran umum lokasi penelitian, studi pendahuluan, hasil wawancara terkait respon masyarakat lokal desa Batu Cermin Labuan Bajo. Data kuantitatif (Sugiyono, 2011) dalam penelitian ini meliputi : luas wilayah Gua Batu Cermin dan jumlah kunjungan wisatawan ke Gua Batu Cermin.

Sumber data dalam penelitian ini meliputi data primer (Sugiyono, 2014) dan data sekunder (Moleong, 2012). Dalam mengumpulkan data peneliti menggunakan tiga teknik meliputi studi kepustakaan (Moleong, 2012) yang digunakan untuk memahami posisi penelitian yang dilakukan peneliti, observasi
(Arikunto, 2010)peneliti turun kelapangan secara langsung untuk mengmati fenomena yang ada dilapangan, dan wawancara( Sarwono, 2006) yang digunakan untuk mengetahui seperti apa respon masyarakat lokal desa Batu Cermin.

Untuk memperoleh data dilapangan dalam penelitian ini peneliti menggunakan prosedur purposive sampling,yaitu Teknik penentuan informan sesuai demgam kriteria yang dipilih yang relevan dengan permasalahan penelitian. Informan yang dimaksud adalah informan harus memiliki pengetahuan tentang kedalaman data terhadap objek penelitian dan informan memilki pengetahuan yang luas terhadap objek penelitian (Bungin, 2007).Dalam penelitian ini informan yang dipilih meliputi kepala dinas kebudayaan dan pariwisata dan kepada desa batu cermin. Teknik analisis data yang digunakan peneliti dalam penelitian ini adalah teknik analisis data deskriptif kualitatif (Bungin, 2007) yaitu dilakukan dengan langkah melakukan pengamatan terhadap fenomena sosial,lingkungan fiik dan ekonomi serta melakukan identifikasi, melakukan kategorisasi terhadap informasi yang diperoleh, menelusuri dan menjelaskan kategorisasi dan menarik kesimpulan umum.

\section{HASIL DAN PEMBAHASAN}

Gua Batu Cermin ditetapkan sebagai daya tarik wisata berdasarkan peraturan Bupati tahun 2008, akan tetapi sebelum itu juga sudah ada kunjungan dari wisatawan. Harga Tiket masuk untuk menikmati atraksi alam yang ada digua batu cermin itu sendiri sangatlah beragam, untuk wisatawan mancanegara dikenakan tarif sebesar Rp. 50.000/orang, wisatawan Nusantara sebesar Rp. 20.000/orang, dan wisatawan lokal Rp. 10.000/orang.

Dalam sistem pengelolan daya tarik wisata Gua Batu Cermin dikelolah oleh dinas Kebudayaan dan Pariwisata Kabupaten Manggarai Barat. Pada tahun ini rencananya pengelolaan Gua Batu Cermin akan melibatkan Desa Batu Cermin dimana pemerintah hanya mengambil retribusi tiket masuk dan sisanya adalah desa batu cermin seperti tempat parkir, sovenir, cafe, dan lain sebagainya. Desa batu cermin sendiri juga sudah memiliki organisasi untuk mewadahi masarakat desa yaitu BUMDES (Badan Usaha Milik Desa) yang telah beroprasi sejak tahun 2018.. Gua Batu Cermin merupakan satu-satunya daya tarik wisata yang ada di desa ini, dalam perkembangan suatu daya tarik dibutuhkan kerjasama antara pihak pengelola dan juga masyarakat lokal agar perkembangannya bisa optimal. Respon dari masyarakat juga menjadi kunci utama agar daya tarik wisata bisa berkembang dan lebih maju dari sebelumnya.

Respon masyarakat dalam penelitian ini ditinjau dari tiga aspek yaitu :
A. Respon masyarakat lokal terhadap pemerintah. 
Vol. 8 No 1, 2019

Gua Batu Cermin dikelolah oleh pemerintah daerah yaitu Dinas Kebudayaan dan Pariwisata KabupatenManggarai Barat. Dalam pengembangannya pemerintah juga menyediakan tempat bagi masyarakat untuk membuka usaha dan berjualan disana. Rencananya pada tahun ini pengelolaan Gua Batu Cermin akan melibatkan Desa Batu Cermin dan juga BUMDES. Desa batu cermin juga sudah berencana akan menambahkan atraksi di daya tarik wisata ini berupa atraksi budaya yang akan di pentaskan dibawah naungan BUMDES yang mana akan melibatkan masyarakat desa.

Di Gua Batu Cermin juga ada Rangger atau pemandu wisata akan tetapi secara sukarela dan belum ada badan atau organsasi yang mewadahi mereka, menurut Sebastianus Ba'a, Kepala Desa Batu Cermin rencanannya pemandu tersebut akan berada dibawahnaungan Bumdes yang nantinya mereka juga akan diberi pelatihan agar lebih meningkatkan mutu pelayanan di Gua Batu Cermin.Dengan adanya daya tarik wisata Gua Batu Cermin sangat berdampak pada perekonomian masyarakat Manggarai Barat khususnya masyarakat desa Batu Cermin apa bila masyarakat lokal lebih pro aktif dalam kegiatan pengembangan disana karena nantinya buah hasil dari kesuksesan Gua Batu Cermin akan dirasakan langsung oleh masyarakat dan juga demi kepentingan desa.

Berdasarkan hasil wawancara dan observasi di daya tarik wisata Gua Batu Cermin respon masyarakat terhadap pemerintah masih berada di tengah-tengah antara positif dan juga negatif, masyarakat desa menilai pemerintah daerah sangat membantu mereka dengan adanya Gua Batu Cermin. Hampir sebagian besar masyarakat desa mendukung pengembangan terhadap daya tarik wisata Gua Batu Cermin. Akan tetapi sebagiannya masih belum sadar dan kurang aktif dalam kegiatan pengembangan daya tarik wisata Gua Batu Cermin karena mereka menilai belum ada dampak langsung yang dirasakan. Adapun masyarakat yang berjualan di daya tarik wisata Gua Batu Cermin merasa dimudahkan oleh pemerintah dengan perijinannya. Pemerintah daerah juga melakukan promosi sehingga bayak wisatawan yang berkunjung ke Gua Batu Cermin dan pada akhirnya berdampak terhadap perekonomian masyarakat desa. Masyarakat desa batu Cermin berharap agar pemerintah selalu melakukan kordinasi bersama masyarakat dan saling membangun sinergitas yang baik dan menjaga kenyamanan dan keamanan.

\section{B. Respon masyarakat lokal terhadap pihak swasta}

Dalam pengembangan daya tarik wisata Gua Batu Cermin pihak swasta yang dimaksudkan adalah agen perjalanan wisata/ agen tour and travel yang berlokasi di Labuan Bajo. Pihak ini tidak hanya mengambil keuntungan dari daya tarik wisata Gua Batu Cermin tetapi mereka juga melakukan promosi secara tidak langsung yaitu dengan menjual paket wisata berkunjung ke Gua Batu Cermin. Masyarakat lokal desa Batu Cermin yakin bahwa pihak swasta ikut mendukung pengembangan daya tarik wisata Gua Batu Cermin karena wisatawan yang berkunjung kegua batu cermin lebih dominan datang karena promisi paket wisata yang ditawarkan oleh pihak agen tour and travel.Masyarakat lokal Manggarai Barat terutama yang bergerak di guide atau Agent Tour and Travel, baik turis domestic maupun guide mancanegara selalu mempromosikan aset-aset wisata yang ada di Manggarai Barat, salah satunya Batu Cermin itu sendiri.Rencananya pada tahun ini BUMDES juga akan ikut melakukan promosi gua batu cermin dengan cara mementaskan keragaman seni dan budaya di setiap akomodasi yang ada di Labuan Bajo sehingga wisatawan dapat mengetahui bahwa tidak hanya atraksi alam saja yang ada di desa batu cermin tetapi juga akan disuguhkan atraksi budayanya.

Berdasarkan hasil wawancara dan observasi yang dilakukan di daya tarik wisata Gua Batu Cermin masyarakat desa menilai pihak ini sangat membantu dalam mendatangkan wisatawan ke Gua Batu Cermin, sebagian besar masyarakat lokal desa batu cermin selalu berkordinasi dengan pihak agen tour and traveldemi meningkatkan kunjungan wisatawan , dengan adanya kunjungan yang banyak dari wisatawan maka perekonomian masyarakat terbantu dan juga pihak swasta ikut mendapatkan keuntungan dari kepuasan wisatawan yang berkunjung ke Gua Batu Cermin.

\section{Respon masyarakat lokal terhadap wisatawan \\ Wisatawan merupakan salah satu bagian} stakeholder dalam sistem kepariwistaan. Dengan adanya kunjungan wisatawan ke suatu daya tarik wisata maka daya tarik tersebut memiliki nilai jualnya sendiri, kunjungan wisatawan juga mempengaruhi berbagai aspek yang dapat mendongkrak kehidupan masyarakat lokal begitupun di daya tarik wisata Gua Batu Cermin. Berdasarkan data kunjungan wisatawan ke daya tarik wisata manggarai barat (Gua Batu Cermin) bulan Januari Juni tahun 2017 dan 2018 yang mendominasi kunjungan ke daya tarik wisata Gua Batu Cermin adalah wisatawan nusantara dengan jumlah 8.572 orang disusul oleh wisatawan mancanegara dengan total 3.065 orang, dan wisatawan lokal berjumlah 1.852 orang. Sayangnya angka kunjungan ini tidak disertai dengan kesadaran masyarakat tentang kebersihan lingkungan,wisatawan yang berkunjung ke Gua Batu Cermin sering complain mengenai kebersihan disana.

Berdasarkan hasil observasi dan wawancara di daya tarik wisata Gua batu cermin, masyarakat desa batu cermin sangat senang dengan kehadiran wisatawan karena wisatawan yang datang membawa dampak baik bagi perekonomian mereka. Dengan adanya kunjungan dari wisatawan barang dagangan 
masyarakat lokal dapat terjual dan masyarakat juga bisa berinteraksi dengan wisatawan secara langsung. Akan tetapi masyarakat di desa batu cermin ada juga yang masih tidak antusias dengan kehadiran dari pariwisata di daerah mereka. Belum adanya keuntungan yang dirasakan secara langsung dari kehadiran pariwisata itu sendiri yang membuat masyarakat menganggap bahwa pariwisata itu adalah biasa saja.

\section{KESIMPULAN}

A. Simpulan

Pada saat ini masyarakat desa Batu Cermin sebagian besar belum begitu antusias dalam mendukung pengembangan daya tarik wisata Gua Batu Cermin. Hanya beberapa saja yang ikut mengambil bagian dalam kegiatan pariwisata disana, ini karena kurangnya kesadaran dari masyarakat desa batu cermin tentang peluang dari pariwisata itu sendiri. Berdasarkan hasil observasi dan wawacara dapat ditarik kesimpulan bahwa masyarakat desa Batu Cermin Berada pada fase Aphaty ini yang dilihat dari masyarakat melakukan interaksi denganwisatawan lebih kearah komersialisasi dan juga perncanaan Gua Batu Cermin masih banyak berkaitan dengan pemasaran untuk meningkatkan kunjungan wisatawan.

Masyarakat desa menilai pemerintah daerah sangat membantu mereka dengan adanya Gua Batu Cermin. Hampir sebagian besar masyarakat desa mendukung pengembangan terhadap daya tarik wisata Gua Batu Cermin. Akan tetapi sebagiannya masih belum sadar dan kurang aktif dalam kegiatan pengembangan daya tarik wisata Gua Batu Cermin karena mereka menilai belum ada dampak langsung yang dirasakan. Dengan adanya daya tarik wisata Gua Batu Cermin sangat berdampak pada perekonomian masyarakat Manggarai Barat khususnya masyarakat desa Batu Cermin, apa bila masyarakat lokal lebih pro aktif dalam kegiatan pengembangan disana karena nantinya buah hasil dari kesuksesan Gua Batu Cermin akan dirasakan langsung oleh masyarakat dan juga demi kepentingan desa.

Begitu pula dengan pihak swasta yaitu Agen Tour and Travel pihak ini tidak hanya mengambil keuntungan dari daya tarik wisata Gua Batu Cermin tetapi mereka juga melakukan promosi secara tidak langsung yaitu dengan menjual paket wisata berkunjung ke Gua Batu Cermin. Masyarakat lokal desa Batu Cermin yakin bahwa pihak swasta ikut mendukung pengembangan daya tarik wisata Gua Batu Cermin karena wisatawan yang berkunjung kegua batu cermin lebih dominan datang karena promisi paket wisata yang ditawarkan oleh pihak agen tour and travel.

Masyarakat desa batu cermin sangat terbantu dengan kehadiran wisatawan karena wisatawan yang datang membawa dampak baik bagi perekonomian mereka. Mereka berharap semua pihak bersinergi demi meningkatkan kunjungan didaya tarik wisata Gua Batu Cermin dan juga ikut membantu menjaga dan melestarikan asset desa batu cermin.

\section{DAFTAR PUSTAKA/REFERENSI}

Arikunto, S. 2010. Prosedur Penelitian: Suatu Pendekatan Praktik (Edisi Revisi). Jakarta: Rineka Cipta.

Bungin, Burhan.2007.Penelitian Kualitatif: Komunikasi, Ekonomi, Kebijakan Publik dan Ilmu Sosial lainnya.Jakarta:Putra Grafika

Budiningtyas, Erna Sadiarti I. 2013. "Showroom Batik Di Kampoeng Batik Laweyan, Respon Masyarakat Terhadap Pengembangan Pariwisata Di Kawasan Cagar Budaya." Jurnal Nasional Pariwisata 5(3): 154-67.

Farhan, Afif. 2019. Cerita Menteri Pariwisata Memilih 10 Bali Baru. https://travel.detik.com/travelnews/d-4522951/cerita-menteri-pariwisatamemilih-10-bali-baru? (diakses 2 Desember 2019)

Karnayanti, N. M. D., \& Mahagangga, I. G. A. O. (2019). Partisipasi Masyarakat Dalam Pengelolaan Desa Wisata Bongkasa Pertiwi Di Kabupaten Badung. Jurnal Destinasi Pariwisata, 7(1).

Kryantono, Rachmat. 2008. Teknik Praktis Komunikasi. Jakarta: Kencana Prenada Media Group.

Laporan Kinerja Instansi Pemerintah Tahun 2018. Dinas Kebudayaan dan Pariwisata Kabupaten Manggarai Barat

Mahagangga, I Gusti Agung Oka. Suryawan, Ida Bagus. Anom, I Putu dan Kusuma Negara, I Made. Evolusi Pariwisata di Indonesia. Turismemorfosis di kabupaten Badung, kabupateng Banyuwangi dan kabupaten Luwu Timur. Denpasar: Cakra Media Utama

Moleong, Lexy J.. 2012. Mertode Penelitian Kualitatif. Bandung: PT Remaja Rosdakarya.

Sarwono, Jonathan. 2006. Metode Kuantitatif dan Kualitatif. Yogyakarta: Graha Ilmu.

Sugiyono. 2011. Metode Penelitian Kuantitatif, Kualitatif dan R\&D. Bandung:Afabeta

Sugiyono. (2014). Metode Penelitian Pendidikan Pendekatan Kuantitatif, Kualitatif, dan R\&D. Bandung: Alfabeta.

Susanto.A. B, 1998. Hobi, Profesi, dan Bisnis. Jakarta : Penerbit GramediaPustaka.

Yoeti,A, Oka . (1996). Pengantar Ilmu Pariwisata. Angkasa, Bandung. 